\title{
Water for firefighting in five South African towns
}

\author{
HM Myburgh and HE Jacobs* \\ Department of Civil Engineering, Stellenbosch University, Private Bag X1, Matieland 7602, South Africa
}

\begin{abstract}
Alternative methods of firefighting and new firefighting technologies could reduce the reliance on potable water supplied via the water distribution system (WDS) for firefighting. Water required for firefighting in 5 towns in proximity to Stellenbosch, South Africa, was evaluated. The key objective of this research project was to investigate the extent to which the WDS was used for fighting fires. The fire flow requirements, specified in South African guidelines, as well as some international standards, were also reviewed. Information from fire departments in 3 municipal areas was analysed to determine the fire type category, the method for extinguishing the fire, and the water requirement to extinguish the fire. Only $8.6 \%$ of all fires were extinguished using water from the WDS by connecting firefighting equipment to a fire hydrant at the time of the fire. Most fires were extinguished by means of water ejected from a pre-filled tanker vehicle disconnected from the WDS at the time of fighting the fire. In most cases water was drawn from the WDS at a predetermined location and time, and then transported by tanker vehicle to the demand point upon receiving an emergency call. This research underlines the need for a hitherto unpublished and more realistic firefighting code for South Africa as it pertains to the WDS.
\end{abstract}

Keywords: fire flow, water distribution system

\section{LIST OF ABBREVIATIONS AND ACRONYMS}

$F_{F} \quad$ - Fire flow volume as per fire record

$F_{T} \quad$ - Initial total tanker volume (firefighting vehicle)

$F_{N} \quad$ - Fire flow volume required from pipe network

WDS - Water distribution system

\section{INTRODUCTION}

\section{Background}

South Africa is currently faced with infrastructure challenges to meet the current demands for service delivery and in particular the provision of water and sanitation. Even though supplying water for potable needs is the main function of a water distribution system (WDS), water is also reserved (as per current standards) to fight fires. To realise the significance of providing water for this purpose, one only needs to consider the damaging effects of a fire.

Numerous methods could be used to extinguish fires. The traditional approach, assumed to be standard practice, involves the provision of water for firefighting via the WDS, as stipulated in South African design guidelines (CSIR, 2003). It is, therefore, important to design a WDS which would ensure that the required flow of water for fighting fires would be readily available for extinguishing fires during an emergency.

Apart from the financial implications of providing the required infrastructure capacity for fire flow in the WDS, provision of water for firefighting via the WDS has other disadvantages. Reserving system capacity for infrequent fire flow may have an adverse impact on the quality of the water. Fire flow

To whom all correspondence should be addressed.

용 +2721 808 4059; Fax: +27 21808 4351;

e-mail: hejacobs@sun.ac.za

Received 22 October 2012; accepted in revised form 2 December 2013. provision necessitates larger pipes and larger reservoirs than would be required in the absence thereof. The increased system capacity remains unutilised during all normal periods of use and the subsequent increased time that water is stagnant in the system would lead to loss of disinfectant and resulting bacterial growth. The larger pipes may also lead to relatively low flow velocities and subsequent deposition of sediments.

\section{Fire progression and the role of water}

Davies (2000) illustrated the progression of fires in buildings by identifying 5 phases: ignition; smouldering; flame growth; fully developed stage and eventual decay, as depicted in Fig. 1. It is obvious that a fire could be extinguished more effectively by tackling it at the correct time. The least productive time to start the fire-extinguishing process would be in the fully developed phase. A fire could be extinguished by eliminating any one of the four components needed to sustain a fire. This could be done by removing the fuel, removing the oxidiser, inhibiting the chain reaction or reducing the temperature. The effectiveness of extinguishing fires is thus a function of the firefighting agents and numerous other factors, such as the stage at which it is tackled and thus the response time, the efficiency of the fire fighter, the fire department, the available equipment and the method used to extinguish the fire. The question arises as to the role of water and the WDS in the process.

Water has long been the most commonly used fireextinguishing agent. The physical properties of water make it ideal for extinguishing most types of fire. Water absorbs heat as it evaporates and also displaces oxygen. It is clear that water is needed for firefighting, but the source of such water is clearly unimportant.

\section{Motivation}

There is a clear need to research the sensibility and scope of fire provision via the WDS. This paper is considered a contribution in this regard. It is important to ensure that the level of fire flow 


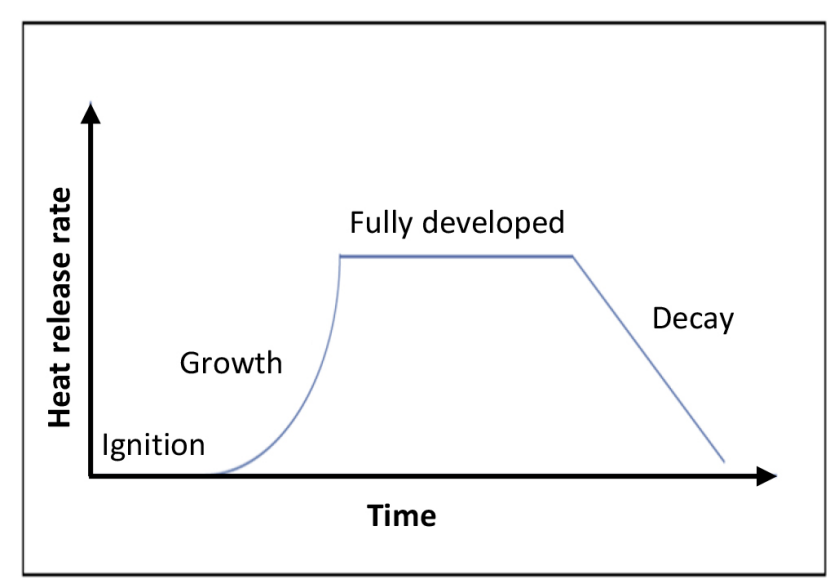

Figure 1

Typical fire progression (Davis, 2000)

required for all areas remains sufficient yet 'realistic' in terms of the current demand and supply in South Africa. This issue was addressed by Van Zyl and Haarhoff (1997), who concluded at the time with the following statement: 'Based on the results reported here... fire water requirements should be considered... with the aim of amending... to more appropriate levels.'

Advanced methods are available to ensure least-cost system design (Filion and Jung, 2010) in the presence of fire flows. However, Jacobs and Strijdom (2009) noted that certain serviced areas in South Africa lack the required residual pressure under peak flow alone. The addition of fire flows to such hydraulic models would, as suggested by local fire flow criteria, increase the peak flow rate in relation to the results by Jacobs and Strijdom (2009) to a point where the WDS would not be able to accommodate conservative fire flow criteria superimposed on the peak water demand. At least some WDS's in the country would not be able to cope with fire flow, and provision thereof as determined by the criteria would be fortuitous. It was beyond the scope of this article to review the extent of the national problem, or to suggest new criteria.

This problem is ostensibly not unique to South Africa. Even though water is one of the least expensive and most available agents for fire extinguishing, Davis (2000) reported, for example, that it would be more cost effective to provide a tanker supply for firefighting as an alternative to the WDS in New Zealand, than to increase the size of the pipes to provide the required fire flow. Van Zyl and Haarhoff (1997) noted that significant cost savings could be achieved by simply lowering the fire water standards to more appropriate levels. In a more complex analysis, Filion et al. (2007) coupled stochastic models of water demand, fire flow, and pipe breaks to derive the most cost-effective system based on minimising the expected annual damages.

\section{Objectives}

The question addressed by this research project was, 'What methods were used by small local authorities to extinguish fires and how often was the WDS employed?' It was hypothesised that the WDS was not used directly for extracting water from hydrants when fighting fires. The main objectives of this study were to:

- Review international standards and published research

- Identify a study area, obtain firefighting records and analyse the data
- Evaluate the techniques used for firefighting and the water requirement for extinguishing fires

- Compare the actual fire flows to current criteria and formerly published values

\section{Study area}

This research was conducted in what could be considered relatively small urban towns in the Western Cape province of South Africa. The towns were selected within a radius of $150 \mathrm{~km}$ from Stellenbosch so as to enable regular visits to the participating fire departments as part of this project, within budget constraints. The data set comprised fire events from 5 towns with population sizes varying between about 5000 and 100000 .

\section{SOUTH AFRICAN CRITERIA AND GUIDELINES FOR FIRE FLOW}

The provision of fire flow and residual water pressures in South Africa is guided by 3 different documents (SANS, 2003; SANS, 2004; CSIR, 2003). Judging by the content of each, the guideline presented by the CSIR (2003) seems to be based on the original revision of the earlier publication (CSIR, 1983) and SABS (1972). A detailed review of the South African firefighting guidelines was presented by Van Zyl and Haarhoff (1997), suggesting at the time that local guidelines were conservative in comparison to those from abroad. The minimum required fire flow by the CSIR (2003) aligns relatively well with the minimum required fire flow of other countries, whereas the minimum required fire flow recommended by SANS (2003) is notably higher.

Van Zyl et al. (2011) noted that very little data on actual firefighting water use has been published, with the cited study being the only local data published prior to this research. Van Zyl et al. (2011) provided results from analyses of actual fire events by analysing 23474 fire event records that remained after filtering, in the City of Cape Town between January 2005 and April 2010. The methods employed to extinguish the fires were not evaluated in the work by Van Zyl et al. (2011), because in that case it was assumed that all fires were extinguished by water abstracted directly from the WDS as it typically the case in large metropoles. Fire frequency and the statistical distributions of fire volumes, durations and flow rates were presented by those authors. Their results based on actual data pertain to one of the largest urban metropolitan areas in South Africa.

South African guidelines for fire flows adopt the conservative approach and neglect alternative non-reticulated supplies.

\section{FIREFIGHTING METHODS AND NOTABLE PARAMETERS}

A comprehensive review of firefighting methods was beyond the scope of this study. In order to understand and present the results of this research, a brief review of selected methods used or referred to in the study area, was included. Notation for describing the most notable parameters is introduced in this section for use in the remainder of the manuscript.

Vehicles (or helicopters) are needed to fight fires as they provide the mode of transport for all other resources, bar water. Water could alternatively be transported to the fire, or within close proximity, via the WDS. The potable WDS is not necessarily needed to extinguish fires. Snyder et al. (2002) 
reported on case-studies where some cities with dual systems used reclaimed water for firefighting in North America. Davies (2000) noted that firefighting water requirements should recognise alternative non-reticulated supplies, if they were available, and these should be factored into the calculations when assessing fire flow requirements.

The following firefighting methods were relevant to this study, or were noted during interviews with fire department staff:

- Buckets - buckets filled with water could be used for manual fire extinguishing.

- Tankers - water could be transported to the fire in prefilled tanker vehicles and ejected directly from the tanker's storage tanks without connection to the WDS at the time of firefighting. Water would be delivered with the aid of booster pumps on the tanker vehicles. The total volume of water available for firefighting from all tankers sent out to the fire combined was denoted $F_{T}$.

- Network - water via the WDS could either supplement $F_{T}$ or replace it. The water could be delivered under pressure from the WDS, or with the aid of booster pumps on the tanker vehicles. The volume of water used from the pipe network to extinguish the fire was denoted $F_{N}$.

- Foam-based methods - the use of so-called Class A foams and a compressed air foam system was reported to make firefighting up to 20 times more effective (Darley, 1995). Class A foams are synthetic detergent hydrocarbon surfactants, which reduce surface tension, causing the volume of the water drop to expand, ensuring that a large volume of each water drop is exposed to the fire which, in turn, results in greater heat absorption. These surfactants emulsify most of the potential barriers that would prevent water penetration, e.g. oil, grease and paints. The bubble characteristics of the foam also increase the extinguishing capabilities of the water-foam mixture. Class A foams are generally used in conjunction with compressed air foam systems. Compressed air foam systems have been reported to reduce the water requirement for extinguishing a fire to $30 \%$ of that needed in the absence thereof, while also reducing the extinguishing time to $25 \%$ of the traditional method. Class B foams are used to extinguish fires on hazardous materials such as flammable liquids and were not noted in this research.

\section{RESEARCH METHODOLOGY}

The study set out to evaluate different methods of providing fire flow and to assess the contribution of the WDS in each case. The research method involved a practical approach to gather data regarding fire events from a number of different towns, with subsequent verification and explanation gained by visiting the appropriate fire departments to discuss the information with knowledgeable staff. The first step was to obtain data from fire departments via e-mail invitation, followed by site visits to those who responded positively.

Requests for fire incident reports, as well as additional information on the occurrence of fires, were sent to 8 fire departments. Each was responsible for a relatively large area, covering a number of towns, surrounding rural areas and roads. Three fire departments responded positively after various follow-up attempts. The fire reports were inconsistent in terms of the format and database fields, but most contained at least the following useful information:

- The time and date of each fire event

- The estimated volume of water that was used to extinguish the fire

- The time required to extinguish the fire

- The method and/or equipment used by the fire department in the process of extinguishing the fire and in some cases also the location of the fire event.

\section{DATA ACQUISITION AND ANALYSIS}

\section{Requests for data and responses}

The data obtained represented 3 different municipalities referred to as A, B and C in this paper (in no particular order). Two of the fire departments also provided useful additional information.

\section{Fire incident reports}

Each fire was described by a fire incident report. Table 1 provides an overview of the acquired data and its relation to the aims of this project. The data were provided electronically for Municipality A and Municipality B and in hard-copy format for Municipality C. In the latter case only those incidents that appeared to be complete were captured. Subsequent to discussion with the fire departments it became clear that all 'major fires' had complete records, so it was assumed for the purpose of this research that the filtered data set included all notable fires, referred to simply as the total number of fires from this point onward. This is important because the contribution of various components addressed in this research is expressed as a percentage of the total number of fires.

The data for all three municipalities was imported into MS Excel and evaluated based on: (i) the type of fire, (ii) fire volume, (ii) average fire flow rate and (iv) whether the WDS was employed during the process of extinguishing the fire. The number of available records with sufficient information for

\begin{tabular}{|l|l|c|c|c|c|c|}
\hline \multicolumn{7}{|c|}{ Overview of available fire incident reports } \\
\hline Municipality & Date range & Number of fire incidents & \multicolumn{3}{|c|}{} \\
\cline { 3 - 7 } & & Total & $\begin{array}{c}\text { Fire type } \\
\text { indicated }\end{array}$ & $\begin{array}{c}\text { Fire volume } \\
\text { could be } \\
\text { derived }\end{array}$ & $\begin{array}{c}\text { Fire flow rate } \\
\text { could be } \\
\text { derived }\end{array}$ & $\begin{array}{c}\text { Sufficient data } \\
\text { to test whether } \\
\text { WDS was used }\end{array}$ \\
\hline A & 1 Jan 2010 - 31 Dec 2010 & 1745 & 78 & 78 & 71 & 78 \\
\hline B & 1 Jan 2010 - 30 Dec 2010 & 705 & 330 & 330 & 330 & 327 \\
\hline C & 1 Jan 2010 - 31 Dec 2010 & $156^{1}$ & 146 & 146 & 145 & 139 \\
\hline Total & - & 2450 & 554 & 554 & 546 & 544 \\
\hline
\end{tabular}

${ }^{1}$ The total was not counted; only those records with near-complete information were captured from hard-copy documents. 
further analysis in each case was included in Table 1. The total volume of water that was used to extinguish the fire $F_{F}$ was divided by the total time duration of the fire event to obtain an average flow rate for each fire event. In some cases the fire volume could be derived, but the duration was missing so that the flow rate could not be derived. Even where average fire flow rates could be concluded from the data set, no indication of the actual maximum flow rates during the firefighting operation was available for any of the incidents. The filtered data set contained 554 fire incidents with flow volumes and 546 for which the flow rate could be derived.

\section{Fire type categories}

The selected fire incident reports included sufficient information to enable a classification of each fire by type. Based on the data provided it was not possible to marry the categories with those formerly used by Van Zyl et al. (2011), which would have made a comparison of the results more significant. In this research the type of fire was described by the following 5 categories: (i) structural fires in the urban area that included all buildings bar informal settlements, (ii) informal settlement fires, (iii) vegetation, grass, veld and refuse fires that were typically beyond the urban edge and thus not in reach of the WDS, (iv) automobile accidents with fires and (v) special services that would include operations like filling swimming pools, fire drills, demonstrations, and so forth.

\section{Methods employed for extinguishing a fire}

Based on discussions with fire department staff, a fire would typically be extinguished in 2 phases. In the first phase the fire would be brought under control and in the second phase care would be taken to ensure that the fire would not flare up again. Since additional information on how long each of these phases took was not provided in the fire incident reports (only the total time duration was recorded in most cases), the total flow rate was assumed to be constant over the time duration, which is similar to the assumption made by Van Zyl et al. (2011) in their study. This calculated average flow rate would probably underestimate the actual peak flow rate during the operation, particularly in instances where fire hydrants were used to refill tanker vehicles during the operation, because the filing operation would be a function of intermittent vehicle arrival and filling rates. Despite this limitation the data were considered the best available and were used without making unjustified assumptions regarding reduced fire durations and subsequently increased peak flow rates. The data set included 544 records that could be used to evaluate whether the WDS was used or not, as discussed below.

\section{RESULTS}

\section{Fire type by category}

Each fire record was categorised by type. The total number of fires in each category per municipality was determined, as presented in Table 2. Some types of fire were typically found beyond the urban edge and beyond the reach of the WDS, thus being less applicable to this research. The columns in the table were grouped accordingly. The category for structural fires included all types of structures (residential, commercial, industrial, etc.). No method could be found to distinguish between the land use types for many incidents and for this reason no attempt was made to distinguish between the land use.

Fires of type 'Veld, grass and refuse' contributed 53\% to the total and typically represented fires where the WDS could not be used directly as these were mainly in non-reticulated areas. A review of fire incidents in New Zealand (Davies, 2000) revealed that only $18 \%$ of fires in the study occurred in nonreticulated areas, suggesting that the contribution by fire type would be site-specific. The results in Table 2 also show that fires in informal settlements contributed almost $15 \%$ to the total by category.

\section{Methodology for evaluating use of the WDS in firefighting}

The different methods for fighting fires of interest to this research were not consistently recorded in the fire incident reports, but it was possible to derive knowledge regarding this aspect from the available information. The following logical method was used to evaluate whether the WDS was used or not: The fire reports indicated the number of vehicles that responded to each fire and also the water tank capacity for each tanker vehicle. It was confirmed that the vehicles were always dispatched to an emergency call with full water tanks. It was thus possible to derive the total volume of water dispatched to a fire scene, $F_{T}$, for each fire incident. The values for $F_{F}$ and $F_{T}$ could be compared, assuming that the WDS would not be needed during a fire if $F_{F} \leq F_{T}$. This would imply that the dispatched vehicles contained more water than was needed to extinguish the fire. Only for fires with $F_{F}>F_{T}$ more water would be needed than was dispatched by road, and an additional water volume $F_{N}$ would be extracted from the WDS during the period of fighting the fire. The only other method noted on the incident reports used in this study was that applied for 4 fires that were extinguished manually (with buckets). These were insignificant in terms of the volume used and it was assumed that buckets were filled with water from

\begin{tabular}{|c|c|c|c|c|c|c|}
\hline \multicolumn{7}{|c|}{$\begin{array}{c}\text { TABLE } 2 \\
\text { Overview of fire incidents per fire-type category per municipality }\end{array}$} \\
\hline \multirow[t]{2}{*}{ Municipality } & \multicolumn{3}{|c|}{ Number of fires within urban area } & \multicolumn{2}{|c|}{$\begin{array}{l}\text { Number of fires beyond urban edge } \\
\text { or unrelated }\end{array}$} & \multirow[t]{2}{*}{ Total } \\
\hline & $\begin{array}{l}\text { Automobile } \\
\text { accidents }\end{array}$ & $\begin{array}{c}\text { Informal } \\
\text { settlements }\end{array}$ & Structural fires & $\begin{array}{l}\text { Veld, grass and } \\
\text { refuse }\end{array}$ & Special services & \\
\hline $\mathrm{A}$ & 6 & 22 & 34 & 16 & 0 & 78 \\
\hline B & 37 & 40 & 35 & 195 & 23 & 330 \\
\hline $\mathrm{C}$ & 18 & 18 & 8 & 84 & 18 & 146 \\
\hline Sub-Total & 61 & 80 & 77 & 295 & 41 & \multirow[t]{2}{*}{554} \\
\hline Total & \multicolumn{3}{|c|}{218} & \multicolumn{2}{|c|}{336} & \\
\hline Contribution (\% of total) & 11.0 & 14.4 & 13.9 & 53.2 & 7.4 & 100 \\
\hline
\end{tabular}




\begin{tabular}{|c|c|c|c|c|c|c|c|c|c|}
\hline \multicolumn{10}{|c|}{$\begin{array}{c}\text { TABLE } 3 \\
\text { Results showing role of WDS in extinguishing fires }\end{array}$} \\
\hline \multirow[t]{3}{*}{ Municipality } & \multicolumn{8}{|c|}{ Number of relevant fire incidents in record period } & \multirow{3}{*}{$\begin{array}{l}\text { WDS used } \\
(\%)\end{array}$} \\
\hline & \multirow[t]{2}{*}{ Total filtered } & \multicolumn{2}{|c|}{$F_{T}$ was not recorded, but: } & \multicolumn{2}{|c|}{$F_{F}$ and $F_{T}$ available } & \multicolumn{2}{|c|}{$\begin{array}{l}\text { Number of fires with } F_{F}>F_{T} \\
\text { that were: }\end{array}$} & \multirow{2}{*}{$\begin{array}{l}\text { WDS used: } \\
\qquad \begin{array}{c}(\mathrm{G})= \\
(A)+(D) \\
-(E)\end{array}\end{array}$} & \\
\hline & & $\begin{array}{l}\text { (A) Flagged } \\
\text { as hydrant }\end{array}$ & $\begin{array}{l}\text { (B) Flagged } \\
\text { as manual }\end{array}$ & $\begin{array}{c}\text { (C) } \\
F_{F} \leq F_{T}\end{array}$ & $\begin{array}{c}\text { (D) } \\
F_{F}>F_{T}\end{array}$ & $\begin{array}{c}\text { (E) } \\
\text { of type } \\
\text { Special } \\
\text { Services }\end{array}$ & $\begin{array}{c}(\mathrm{F}) \\
\text { On farmland } \\
\text { beyond } \\
\text { urban edge }\end{array}$ & & \\
\hline A & 78 & 8 & 4 & 55 & 11 & 0 & 2 & 19 & 24.4 \\
\hline B & 327 & 0 & 0 & 312 & 15 & 5 & 5 & 10 & 3.1 \\
\hline $\mathrm{C}$ & 139 & 0 & 0 & 118 & 21 & 3 & 14 & 18 & 12.9 \\
\hline Total & 544 & 8 & 4 & 485 & 47 & 8 & 21 & 47 & 8.6 \\
\hline
\end{tabular}

${ }^{1}$ Expressed as a percentage of the total filtered fire incidents.

\begin{tabular}{|l|c|c|c|c|c|}
\hline \multicolumn{7}{|c|}{ TABLE 4 } \\
\hline Symme category & $\begin{array}{c}\text { Automobile } \\
\text { accidents }\end{array}$ & $\begin{array}{c}\text { Informal } \\
\text { settlements }\end{array}$ & Structural fires & $\begin{array}{c}\text { Veld, grass and } \\
\text { refuse }\end{array}$ & Special services \\
\hline Average flow volume $(\mathrm{k} \ell)$ & 2.5 & 4.4 & 8.6 & 4.1 & 8.6 \\
\hline Maximum flow volume $(\mathrm{k} \ell)$ & 10.0 & 50.0 & 120.0 & 100.0 & 100.0 \\
\hline Average flow rate $(\ell / \mathrm{min})$ & 69 & 91 & 110 & 74 & 93 \\
\hline Maximum flow rate $(\ell / \mathrm{min})$ & 167 & 417 & 1200 & 246 & 300 \\
\hline
\end{tabular}

an unknown source, not the WDS. Excluding these 4 cases, the volumes could thus be expressed as $F_{F} \leq F_{T}+F_{N}$. The results, segregated per municipality as presented in Table 3 , include the following:

- The total number of filtered records included all fire incident reports with sufficient information to establish whether the WDS was used or not.

- For some records $F_{T}$ was not recorded, but the incident report indicated instead that either a fire hydrant attached to the WDS (Column A) or a manual method (Column B) was used to extinguish the fire.

- The number of records with $\left(F_{F} \leq F_{T}\right)$ and also $\left(F_{F}>F_{T}\right)$ were respectively listed as Column $(\mathrm{C})$ and Column (D).

- Water would not have been needed from the WDS during an actual fire event for all fires with $F_{F}>F_{T}$, because some of these were flagged as type category 'Special Service' as recorded in Column (E). These were excluded when calculating the number of fires simply because they did not represent actual emergencies.

- The number of fires with $F_{F}>F_{T}$ that were noted to be beyond the urban edge were listed in Column (F). Discussion with fire department staff indicated that water would have been abstracted from the WDS for such fires, since the tanker vehicles would shuttle from the fire to the closest hydrant at the urban edge for refilling during the firefighting process.

- Column (G) shows the number of fires where use of the WDS was considered likely.

Only 47 fires (8.6\% of the total) were recorded that suggest use of the WDS during firefighting. Fires beyond the urban edge were listed in column (F), Table 3 , and comprised 21 of these instances (45\%). The results showed that $24 \%, 3 \%$ and $13 \%$ of the fires were extinguished using the WDS in the three municipalities A, B and C, respectively; Municipality A with the largest percentage also represented the largest town in the study area.

\section{Fire flow volume and flow rate}

The average and maximum fire flow volume and flow rate for each fire category were determined as shown in Table 4.

The cumulative probability plots for all 554 fire flow volumes (Fig. 2) and all 546 derived fire flow rates (Fig. 3) were compiled. The resulting curve for the fire volumes is similar to that presented by Van Zyl et al. (2011) for a much larger metropoli$\tan$ area, but the flow rates are notably lower for the small towns than those presented by Van Zyl et al. (2011).

Figure 2 presents fewer plotted points than Fig. 3, despite the analysis being based on more records. This is because fire volumes were often rounded upon initial entry to significant numbers implying that that some points coincide on Fig. 2 . The two volumes that represent most of these incidents were $1000 \mathrm{l}$ (with 143 instances reported) and $2000 \ell$ (with 81 instances). The flow rate was subsequently derived as a function of the fire duration.

As could be expected the 8 fires where hydrants were specifically indicated as per Table 3 , Column (A), were notable in terms of the volume (including the second largest and 4 of the top 10 volumes) and the flow rate (including the 3 largest flow rates).

\section{DISCUSSION}

The use of fire hydrants for extinguishing fires was only indicated on eight of the fire incident reports, all in Municipality A. This could incorrectly be interpreted to mean that only 8 fires (1.4\% of fires) were extinguished with water abstracted from the WDS, whereas these 8 fires were in fact extinguished with water abstracted directly from the WDS during the firefighting process. Based on the analyses, $91.4 \%$ of fires with complete data in the fire incident reports were extinguished with non-reticulated water supplies. This does not suggest that water supply from the WDS for firefighting is unimportant. The most notable fires in terms of total volume 


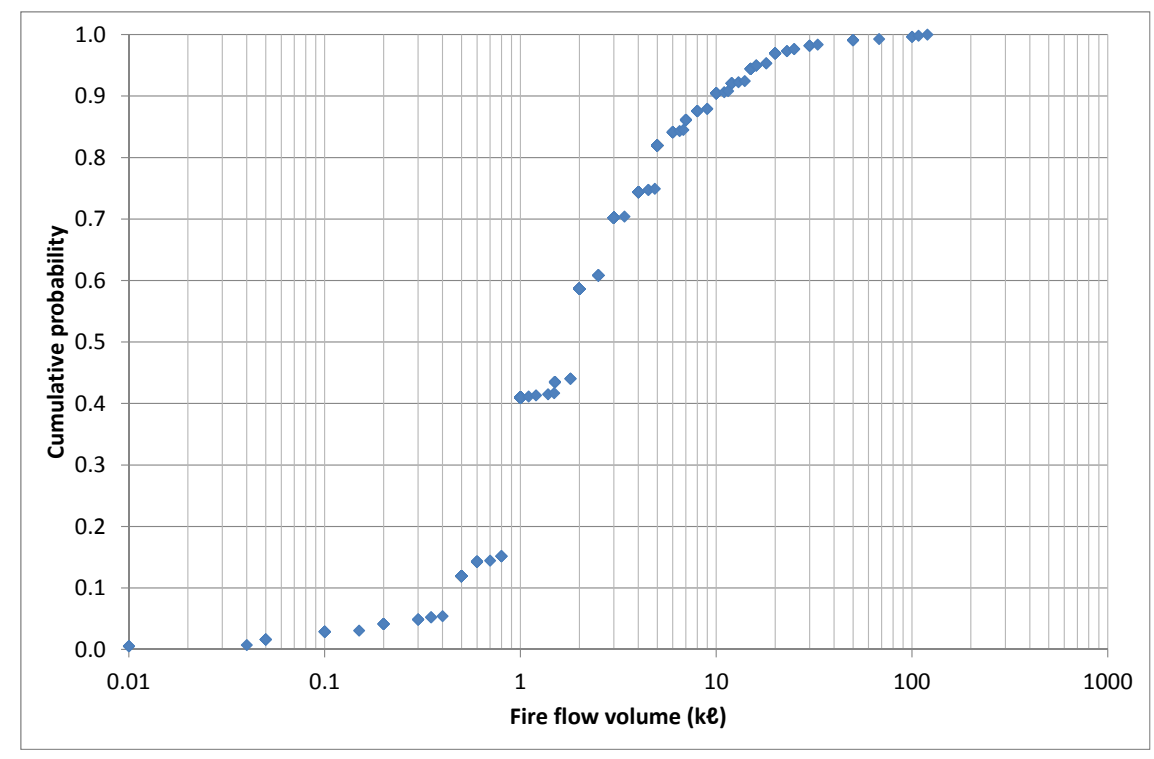

Figure 2

Cumulative

probability plot for all

fire flow volumes

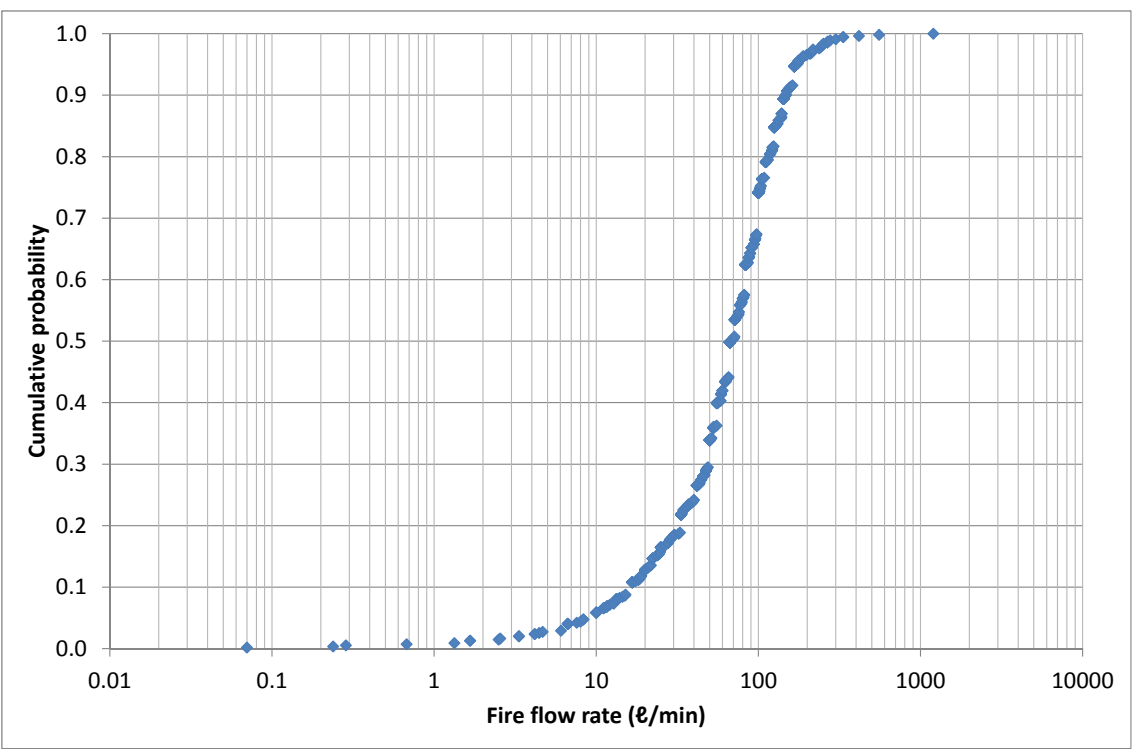

of water required and the flow rate were the ones where the WDS was employed. Accordingly it does not imply that the WDS was not used, because the tanker vehicles were filled at some stage with potable water from the WDS in all instances. Similar results were presented by Davies (2000) who found that, over a 3 -year period, on average $96 \%$ of structural fires in that study area were either extinguished with non-reticulated water supplies or with less than $10 \mathrm{l} / \mathrm{s}$ of reticulated water supply.

A relatively large percentage of fires within the urban edge (14.4\% of the total) occurred in informal settlements, with relatively high flow rates and volumes reported on average for these fires. Although informal settlement fires do not essentially result in high property losses or insurance claims, these fires are potentially most threatening to society due to the close proximity of the residences and high population density in these areas - often coupled with narrow and inaccessible roads. In contrast to the relatively high local fire flow standards, the CSIR (2003) proposed no fire flow requirement from the WDS for low-risk areas, which were defined as 'Residential areas where the gross floor area of the dwelling house, including outbuildings, is generally not more than $55 \mathrm{~m}^{2}$. The low-risk category would per definition include low-cost housing (LCH) schemes. This is a paradox given the prevalence of fires reported for dense settlements in this study. According to previous studies done for urban areas, such as Johannesburg (Van Zyl and Haarhoff, 1997) and Cape Town (Van Zyl et al., 2011), fire flow requirements for high-risk areas were determined to be unnecessarily high, whereas the requirements for low-risk areas were noted to be inadequate. This study underlines those findings. Flow rates for fighting fires were found to be notably lower for all three municipalities than the fire flows required in the South African standards.

Comparison of the cumulative probability plots from the small towns as per this study with a large urban metropolitan area reported on earlier (Van Zyl et al., 2011), suggests that fire flow rates are significantly lower in small towns than cities, but fire flow volumes are practically the same in both cases. A striking difference was noted in the method employed to fight a fire, suggesting that small towns do not use hydrants connected to the WDS directly during the process of fighting a fire as often as is done for the large urban metropolitan area. Also, a notable number of fires beyond the urban edge required water to be abstracted from the WDS. 


\section{CONCLUSION}

Water is but one substance that could be used to extinguish a fire. The potable distribution system is but one vehicle to transport water to a fire. A total of 554 fire incidents from 3 municipalities representing 5 relatively small towns were analysed as part of this research. All fires were extinguished using water.

The WDS was seldom used during emergency operations to extinguish fires in the study area, even within the reticulated area. The WDS was used directly to extinguish 47 fires, or $8.6 \%$ of the total number of fires. It was found that fire fighters transported water from the fire station via pre-filled tanker vehicles as the first line of defence in all cases when attending to a fire call. In cases where the required volume would exceed the dispatched tanker volume, the vehicles would shuttle to a sensible location at a fire hydrant for refilling during the operation. The hydrant selected would be the closest easily accessible one to the scene of the fire, which in most cases was at the urban edge. Current standards require a WDS to be able to provide the required fire flows at all nodes in the WDS. It would be invaluable to better understand the spatial attributes of fires, but the fire incident reports available did not provide sufficient data to enable an analysis of this nature.

Increased future application of alternative methods for firefighting would reduce the reliance on potable water sources for fighting fires, freeing this precious natural resource to sustain human life. Water provision for firefighting from the potable WDS will be needed until alternatives for firefighting become more feasible in terms of cost.

\section{ACKNOWLEDGEMENTS}

The authors would like to thank the various municipalities, fire brigades and their staff for kind cooperation. A 2-year grant towards full time post-graduate research was provided by the Stellenbosch University's Overhead Strategic Plan (OSP) and is greatly acknowledged.

\section{REFERENCES}

CSIR (2003) Guidelines for Human Settlement Planning and Design. Report compiled for the Department of Housing. Building and
Construction Technology, Council for Scientific and Industrial Research, Pretoria.

CSIR (1983) Guidelines for the provision of engineering services for residential townships. Report compiled for the Department of Community Development. Council for Scientific and Industrial Research, Pretoria.

DARLEY P (1995) The use of "A" foam and compressed air foam systems (CAFS) in fire fighting. Foam Applications for Wildland and Urban Fire Management Vol. 7. National Wildfire Coordinating Group, USA. 15-22.

DAVIES SK (2000) Fire fighting water: A Review of fire fighting water requirements - A New Zealand perspective. M.E. thesis, Fire Engineering Research Report 2000/3, February 2000, School of Engineering, University of Canterbury, Christchurch, New Zealand.

FILION Y, ADAMS B and KARNEY B (2007) Stochastic design of water distribution systems with expected annual damages. J. Water Resour. Plann. Manage. 133 (3) 244-252.

FILION Y and JUNG B (2010) Least-cost design of water distribution networks including fire damages. J. Water Resour. Plann. Manage. 136 (6) 658-668.

JACOBS HE and STRIJDOM JL (2009) South African fire water guidelines and their impact on water supply cost system. Water SA 35 (2) $183-191$.

SABS (SOUTH AFRICAN BUREAU OF STANDARDS) (1972) South African Bureau of Standards, SABS 090:1972. Pretoria, South Africa.

SANS (SOUTH AFRICAN NATIONAL STANDARDS) (2003) South African National Standards 10090:2003 ( $3^{\text {rd }}$ edn.) Standards South Africa, Pretoria.

SANS (SOUTH AFRICAN NATIONAL STANDARDS) (2004) South African National Standard: Water supply and drainage for buildings 10252:2004. Standards South Africa, Pretoria.

SNYDER JK, DEB AK, GRABLUTZ FM and McCAMMON SB (2002) Impacts of fire flow on distribution system water, quality, design and operation. AWWA Research Foundation Report 2554. American Water Works Association, Denver.

VAN ZYL JE, DAVY M and HAIHAMBO F (2011) Water used for fire fighting in Cape Town. Proc. 11th International Conference on Computing and Control for the Water Industry: Urban Water Management: Challenges and Opportunities, Centre for Water Systems, 5-7 September 2011, University of Exeter.

VAN ZYL JE and HAARHOFF J (1997) South African fire water guidelines and their impact on water supply cost system. J. S. Afr. Inst. Civ. Eng. 31 (1) 16-22. 
http://dx.doi.org/10.4314/wsa.v40i1.2 Available on website http://www.wrc.org.za

ISSN 0378-4738 (Print) = Water SA Vol. 40 No. 1 January 2014 ISSN 1816-7950 (On-line) = Water SA Vol. 40 No. 1 January 2014 